\title{
GEOTECNOLOGIAS APLICADAS À ESTIMATIVA DO COMPORTAMENTO DO SALDO DE RADIAÇÃO EM DIFERENTES USOS DA TERRA EM ÁREAS DE CERRADO (MG)
}

\section{Geotechnologies applied to the radiation balance behavior estimation in different land uses in Cerrado areas (MG)}

\author{
Lucas Augusto Silva \\ Acadêmico em Geografia na Universidade Estadual de Montes Claros (UNIMONTES) \\ lucaskaio1605@gmail.com \\ Manoel Reinaldo Leite \\ Mestre em Geografia (em Cartografia e Sensoriamento remoto) pela UFU \\ leitemanoelreinaldo@gmail.com
}

Artigo recebido em 18/09/2017 e aceito para publicação em 09/11/2017

DOI: $10.12957 /$ tamoios.2017.30449

\section{RESUMO}

Este trabalho se norteou em entender o comportamento do saldo de radiação diário (Rn24h) em diferentes usos da Terra na bacia hidrográfica do rio São Lamberto, no Norte de Minas Gerais. Foram feitas análises com técnicas de Geoprocessamento e SIG, utilizando dados de sensoriamento remoto dos Satélites Landsat-5 TM e 8 (OLI/TIRS). Buscou analisar um intervalo temporal de 31 anos, entre 1985 e 2016, a fim de acompanhar as modificações do uso da Terra e estabelecer parâmetro da variação do saldo de radiação diário em diferentes usos da Terra. Obteve resultados significativos da tendência do saldo de radiação, sendo maior em áreas de vegetação nativa e eucalipto e, tendo os menores valores nas áreas de solo exposto/pastagens degradadas e Urbano e porções de pastagens.

Palavras-Chave: Saldo de radiação, Uso da Terra e Bacia Hidrográfica do Rio São Lamberto.

\begin{abstract}
This work was aimed at understanding the behavior of the daily radiation balance ( $\mathrm{Rn} 24 \mathrm{~h})$ in different Land uses in the basin of the São Lamberto river, in the North of Minas Gerais. Analyzes were performed using Geoprocessing and GIS techniques, using remote sensing data from Landsat-5 TM and 8 (OLI / TIRS) satellites. It sought to analyze a time interval of 31 years, between 1985 and 2016, in order to follow the modifications of the Land use and establish parameter of the variation of the balance of daily radiation in different land uses. It obtained significant results of the trend of the radiation balance, being higher in areas of native vegetation and eucalyptus, and having the lowest values in the areas of exposed soil / degraded pastures and Urban and pasture portions.
\end{abstract}

Key Words: Balance of Radiation, Land Use and São Lamberto River Basin. 


\section{INTRODUÇÃO}

Dentro do vasto campo da climatologia geográfica, a modelagem de parâmetros biofísicos na superfície terrestre se torna imprescindível para analisar as variações dos fenômenos climáticos no globo terrestre.

Dentre as variáveis climáticas destaca-se o Balanço de Radiação. Entender a dinâmica ocorrida neste fenômeno se torna de suma importância para o gerenciamento e planejamento ambiental, principalmente tangente às questões hídricas, sendo que, segundo Silva et al. (2005), trata-se do processo responsável pelas trocas de calor e massa na troposfera, uma vez que constitui o principal responsável pelo aquecimento do solo, do ar e, sobremaneira, pela evapotranspiração da vegetação nativa e das culturas.

Este fenômeno é altamente influenciado por vários fatores, entre eles, a exploração antropogênica à superfície (principalmente por meio de mudanças nos sistemas de usos da Terra) se torna fator principal nas alterações do balanço de radiação. As mudanças no uso e ocupação da terra em bacias hidrográficas podem provocar substanciais alterações no balanço de energia e, por conseguinte, afetar a evapotranspiração e até mesmo o clima localmente (FOSTER et al., 2007).

Segundo Souza et al. (2008) as variações no saldo de radiação são fundamentais nos processos atmosféricos e terrestres alterando, por exemplo, a temperatura na superfície, o perfil da taxa vertical de aquecimento e a circulação atmosférica.

$\mathrm{O}$ saldo de radiação resulta no balanço entre os fluxos radiativos descendentes e ascendentes de onda curta e onda longa, que atuam na superfície e depende bastante da radiação solar global, do albedo, temperatura e emissividade da superfície, apresentando variação temporal e espacial que impactam fortemente as trocas de calor e massa na baixa atmosfera. Sua determinação direta pode ser feita com radiômetros; no entanto, essas medições são representativas de áreas de pequena dimensão e boa homogeneidade e, ademais, os custos de aquisição e manutenção são elevados, o que restringe sua ampla utilização (SILVA et al., 2011).

E tendo em vista que, a quantificação de dados sobre saldo de radiação é de grande valia para compreender as interações na biosfera-atmosfera (BISHT e BRAS, 2010), surgem técnicas que suprem a necessidade de estimar o saldo de radiação em larga escala espacial e podendo avaliar as heterogeneidades na superfície, entre estas técnicas, se destaca o sensoriamento remoto, que para Silva et. at., (2005) vem assumindo grande destaque no monitoramento de diversos fenômenos meteorológicos, subsidiando as previsões do tempo e, de uma forma indireta, proporcionando um melhor entendimento sobre as mudanças climáticas.

Entende-se o sensoriamento remoto como a forma de obter informações sobre alvos na superfície sem que haja contato com os mesmos, através da interação de radiação eletromagnética.

Diante disto, os avanços tecnológicos vêm fomentando melhores aplicações em conjunto com o sensoriamento remoto para obter com êxito resultados sobre as variações climatológicas, entre estes avanços cita-se o algoritmo SEBAL (Surface Energy Balances Algorithm for Land), proposto por Bastiaanssen em 1995.

O algoritmo SEBAL faz uso das radiâncias espectrais registradas em sensores (TM, ETM+, ASTER, AVHRR, MODIS, OLI/TIRS) de satélites que proporcionam a determinação da temperatura da superfície, do albedo e de índices de vegetação. São requeridos, ainda, poucos dados meteorológicos de superfície, que incluem a velocidade do vento, temperatura do ar e radiação solar global. Com tais informações, são determinados os balanços de radiação e de energia, quando então se obtém o fluxo de 
calor latente como resíduo do balanço de energia (BASTIAANSSEN et al., 1998b, 2005; SILVA et al., 2012).

Face exposto, este trabalho se norteou em entender o comportamento do saldo de radiação diário $(\mathrm{Rn} 24 \mathrm{~h})$ em diferentes usos da Terra, na bacia hidrográfica do rio São Lamberto, no Norte de Minas Gerais. Este estudo dispôs do emprego de técnicas de sensoriamento remoto e algoritmo SEBAL, utilizando dados orbitais dos satélites Landsat-5 TM e 8 (OLI/TIRS). Buscou analisar um intervalo temporal de 31 anos, entre 1985 e 2016, a fim de acompanhar as modificações do uso da Terra e estabelecer parâmetro da variação do saldo de radiação diário em diferentes usos da Terra.

A escolha da área de estudo, se justifica porque a bacia hidrográfica como recorte espacial para as análises das variações dos parâmetros geofísicos tem sido utilizada constantemente em diversos prismas da modelagem climatológica.

\section{MATERIAIS E MÉTODOS}

\section{Caracterização da área de estudo}

A bacia hidrográfica do rio São Lamberto situa-se entre os paralelos de $16^{\circ}$ $45^{\prime} 00^{\prime \prime}$ e $17^{\circ} 15^{\prime} 00^{\prime \prime}$ de latitude sul entre os meridianos de $44^{\circ} 0^{\prime} 00^{\prime}$ ' e $42^{\circ} 20^{\prime} 0$ ' ' de longitude oeste. O rio principal desta rede de drenagem, o São Lamberto, é afluente da Margem esquerda do rio Jequitaí (ALMEIDA et. al., 2017). Sua extensão territorial compreende 4 municípios da mesorregião Norte-mineira, que são eles, Montes Claros, Claro dos Porções e São João da Lagoa e Jequitaí (IBGE, 2010). Tangente aos parâmetros topográficos, a altimetria da bacia hidrográfica do Rio São Lamberto varia entre 564 e 1088 metros, sendo possível discutir acerca da instalação de sistemas agropastoris nas áreas mais planas da bacia, na figura 1 está demonstrada a altimetria da bacia:

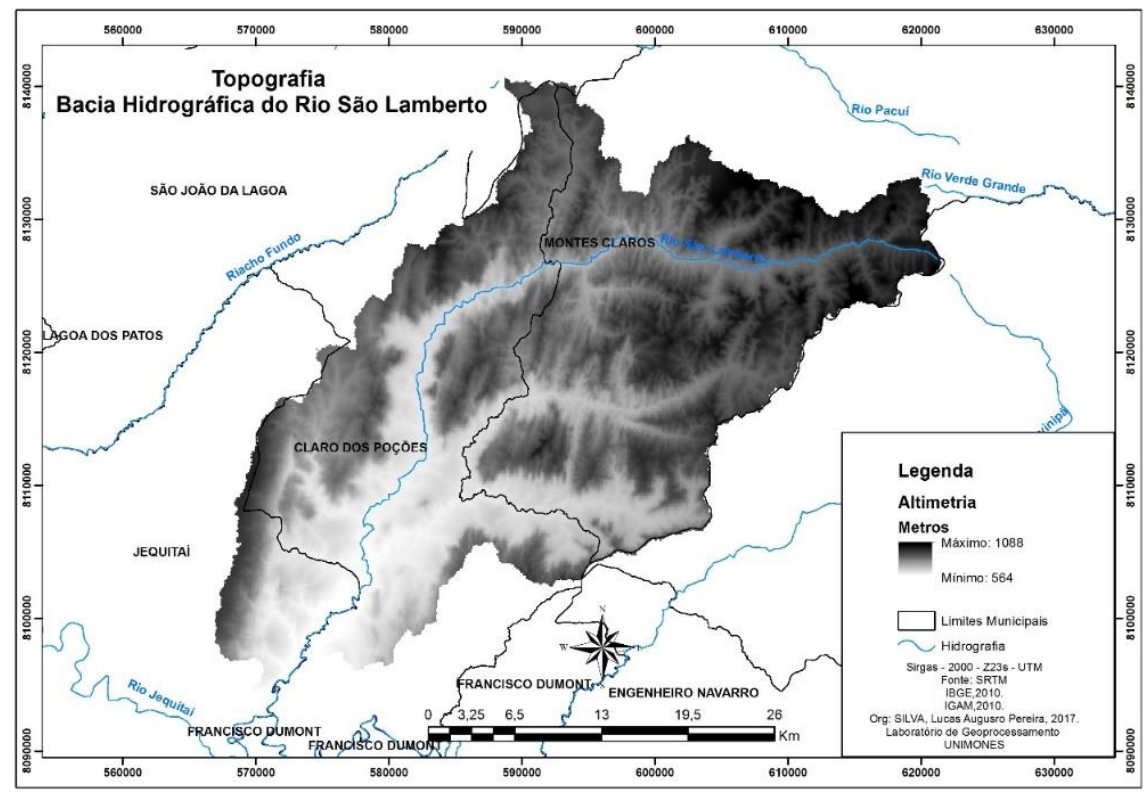

Figura 1- Topografia da área de estudo.

A Bacia Hidrográfica do Rio São Lamberto é composta por relevos das Chapadas do Rio São Francisco, da Depressão do Alto-Médio Rio São Francisco (IBGE,2010). No Tocante às características da fitofisionomia desta bacia, a vegetação é composta por: Cerrado Sensu Stricto, Mata ciliar, Cerrado em regeneração e Mata Seca. O clima da 
região, de acordo com a classificação de Köppen, é do tipo Aw - clima tropical chuvoso, com estações seca e chuvosa bem definidas. A temperatura média anual é de cerca de $23^{\circ} \mathrm{C}$ e a precipitação média é de aproximadamente $1.000 \mathrm{~mm}$ ao ano, com chuvas concentradas nos meses de novembro a janeiro. De acordo com a EMBRAPA (2006) a classificação dos solos da região é latossolo vermelho escuro (LE) e vermelho-amarelo.

\section{PROCEDIMENTOS TÉCNICOS OPERACIONAIS}

Para execução desta pesquisa seguiu-se as seguintes etapas:

- Aquisição de imagens dos satélites Landsat 5 TM e 8 (OLI/TIRS) na plataforma digital do INPE (Instituto Nacional de Pesquisas Espaciais) referentes as seguintes datas:28/08/1985 e 16/07/2016.

- Aquisição de bases cartográficas junto a plataforma digital do IBGE (Instituto Brasileiro de Geografia e Estatística).

- Delimitação da bacia hidrográfica.

- Mapeamento do uso da Terra na bacia a fim de analisar os usos da Terra e sua evolução.

- Mapeamento do saldo de radiação diário.

Para execução destas etapas foram utilizados softwares de processamento digital de imagens (PDI), SIG e estatística aplicada, que são: Erdas IMAGINE e ArcMap 10.3.1, Excel 2013, respectivamente, além do auxílio do algoritmo SEBAL.

\section{DELIMITAÇÃO DA BACIA HIDROGRÁFICA}

Nesta esta etapa, foram utilizados dados de altimetria do Shuttle Radar Topography Mission (SRTM), disponível no site: Topodata. Utilizando as folhas SE-23X-A e SE-23-X-C para extração automática da bacia. Esta extração automática consistiu nas seguintes etapas apresentadas na figura 2:

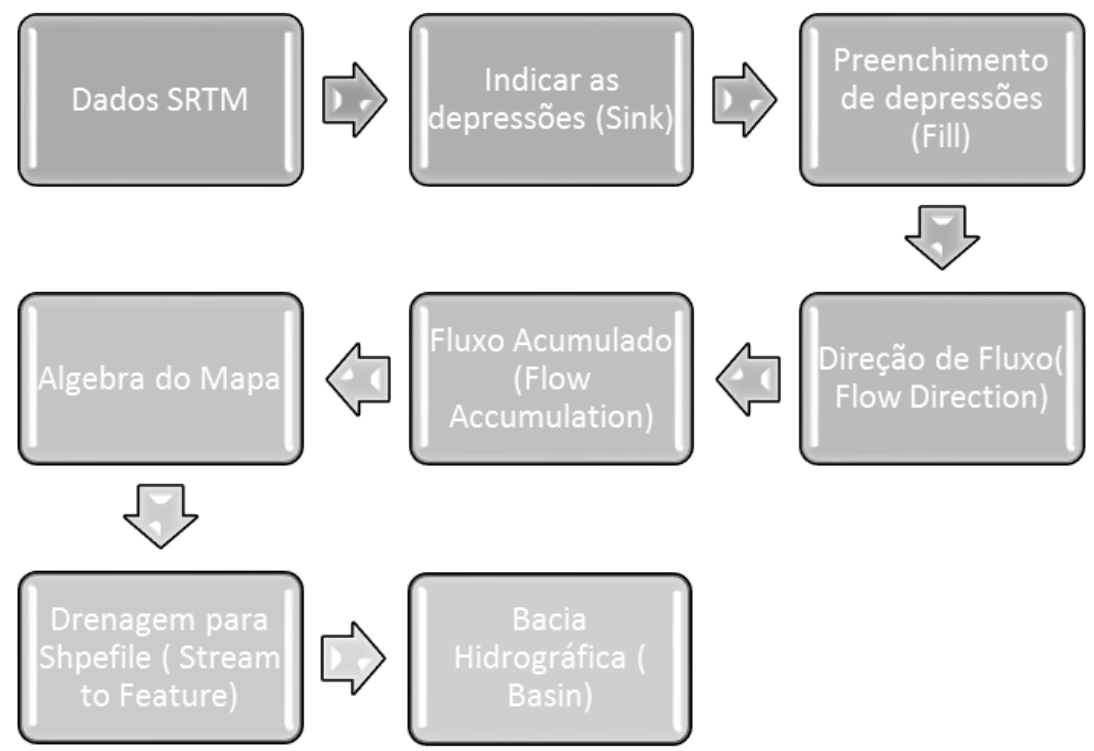

Figura 2- Etapas para extração da bacia hidrográfica.

Este processo foi realizado através da extensão Spatial Analyst, e ferramenta Hydrology, do Arcmap 10.3.1.Logo após este procedimento, seguiu-se as etapas listadas na figura 2. 
- SINK: Cria um raster identificando todas as depressões, áreas de drenagem interna e vazios ou erros do SRTM ou outro raster de superfície.

- FILL: Preenche pequenas imperfeições nos dados e remove todos os sinks do Raster de superfície.

- FLOW DIRECTION: Para definir as relações hidrológicas entre pontos diferentes dentro de uma bacia.

- FLOW ACCUMULATION: para definir o grau de confluência do escoamento associado ao comprimento de rampa, ou seja, a área de captação.

- ALGEBRA DO MAPA: Esta expressão matemática é criada com base em preposições que podem surgir ao decorrer do trabalho. A função $C O N$, determina um teste lógico e retorna um resultado. No que tange a uma rede de drenagem, cria-se uma condição para criar o limiar, filtrando apenas os pixels significativos. Seguindo as etapas: Spatial Analyst- Map AlgebraRaster Calculator, abrirá no ArcMap 10.3.1 o espaço para inserir a expressão lógica (matemática): Con ("FLOW_ACCUMULATION.tif "> $500,1)$, após isto, a rede de drenagem será visualizada na plataforma do ArcMap.

- STREAM TO FEATURE: Esta etapa consiste na vetorização da drenagem.

- BASIN: Esta etapa consiste na extração da bacia hidrográfica.

\section{MAPEAMENTO DO USO DA TERRA}

O mapeamento do uso da Terra, foi feito por classificação supervisionada que, na concepção de Novo (2008) o analista tende a estar constante interação com o sistema de análise digital, dispondo de informações sobre a cena (área de estudo).

Através do classificador MaxVer, a classificação por máxima verossimilhança (MaxVer) considera a ponderação das distâncias entre a média dos valores dos pixels das classes, utilizando parâmetros estatísticos (Lillesand, Kiefer e Chipman, 2007). Nessa classificação cada pixel é destinado à classe que tem mais alta probabilidade de ser similar, ou seja, a máxima verossimilhança. É um classificador mais eficiente porque são utilizadas classes de treinamento para estimar a forma de distribuição dos pixels contidos em cada classe. (MENESES; SANO, 2012, p. 205).

A fim de obter dados fidedignos o mapeamento do uso da Terra teve como base comparativa o projeto TerraClass Cerrado 2013, elaborado pelo INPE e EMBRAPA para o Cerrado Brasileiro, entretanto, o raster do TerrClass foi adaptado (figura 3) para as classes com maior expressão nesta pesquisa, como o Cerrado e as pastagens. 


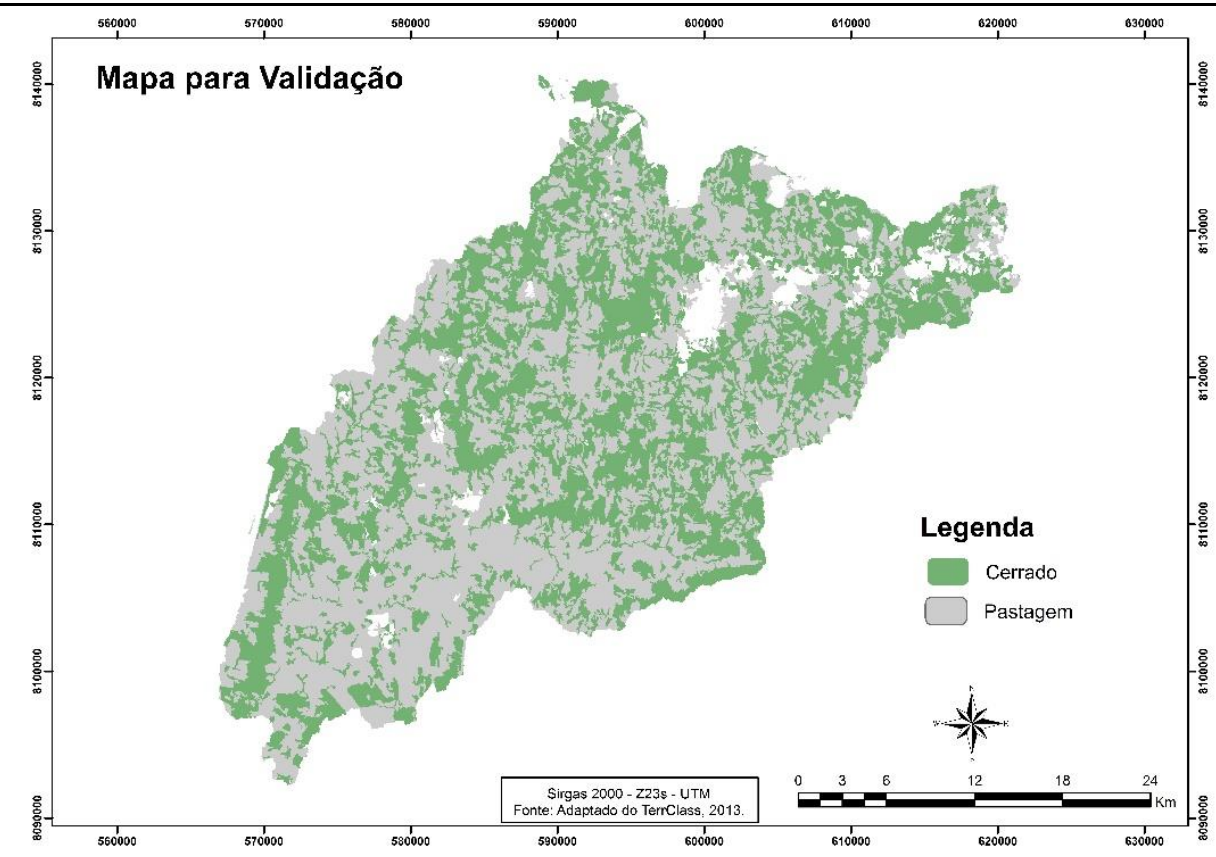

Figura 3 - Mapa de Validação

O mapa adaptado do TerraClass apresenta grande similaridade com o uso da Terra estabelecido para o mapeamento desta pesquisa, entretanto, as áreas não expostas na figura 2, foram avaliadas através do Google Earth. Sobretudo, este mapeamento também teve auxílio de base bibliográfica, analisando os mapeamentos realizados por Almeida et al., (2017) e Fernandes (2012) na mesma área de estudo. É importante explicitar que na figura 3, as áreas aparentemente em branco, não fazem referência a nenhuma classe, é somente o plano de fundo da plataforma do Arcmap 10.3.1.

Após a análise conceitual da base cartográfica do TerraClass, foram elaborados os mapas temáticos de uso e cobertura da Terra para a bacia considerando a temporalidade estabelecida (31 anos), ou seja, mapas temáticos de 1985 e 2016.Após a análise conceitual da base cartográfica do TerraClass, foram elaborados os mapas temáticos de uso e cobertura da Terra para a bacia considerando a temporalidade estabelecida (31 anos), ou seja, mapas temáticos de 1985 e 2016.

Para este mapeamento do uso da Terra, foram selecionadas as seguintes classes de uso da Terra: Cerrado, Eucalipto, Mata Seca, Pastagem, Solo Exposto e Urbano, que estão explicitadas na tabela 1:

\begin{tabular}{|c|c|}
\hline Usos da Terra & Características \\
\hline Cerrado & $\begin{array}{l}\text { A classe cerrado, é caracterizada por uma vegetação com variadas } \\
\text { fitofisionomias. Vegetação densa, espaçada, em topos de serras, matas } \\
\text { ciliares e entre outros. }\end{array}$ \\
\hline Eucalipto & $\begin{array}{l}\text { Dentro desta classificação, estão as áreas estendidas aos topos de serras na } \\
\text { bacia mapeada. }\end{array}$ \\
\hline Mata Seca & $\begin{array}{l}\text { Possui características de vegetação espaçada, arbustiva e de pequeno e } \\
\text { médio porte. }\end{array}$ \\
\hline Pastagem & Dentro desta classe estão as áreas de pastagens, espaçadas e ralas. \\
\hline Solo Exposto/Pastagens degradadas & $\begin{array}{l}\text { Dentro desta classe, estão as áreas cujo o solo está descoberto de } \\
\text { vegetação, seja ela nativa ou antrópica, pastagens degradadas, com sua } \\
\text { formação vegetal fragmentada. }\end{array}$ \\
\hline Urbano & $\begin{array}{l}\text { Esta classe compreendeu as áreas das edificações, tanto das áreas das } \\
\text { cidades, quanto distritos e entre outros. }\end{array}$ \\
\hline
\end{tabular}

Tabela 1- Características das classes de uso da Terra 
Após este mapeamento, seguiu-se a lógica de retirar pontos amostrais nos produtos orbitais, a fim de mensurar o comportamento do Saldo de Radiação nos diferentes usos da Terra e representar por meio de gráficos.

As demais etapas consistiram no mapeamento do saldo de radiação diário à superfície por meio de comandos do algoritmo SEBAL.

\section{ALGORITMO SEBAL (SURFACE ENERGY BALANCES ALGORITHM FOR LAND)}

O Algoritmo SEBAL descreve o balanço de radiação e energia à superfície, através das bandas do espectro do visível, infravermelho próximo e médio e Termal. Estes canais são utilizados como entrada no processo técnico operacional das imagens, em conjunto dos dados de estações meteorológicas que estejam no interior da cena.

O SEBAL foi testado e validado em diversas regiões do globo como, por exemplo, E.U.A, China, Egito, Espanha, Argentina, Índia, Brasil entre outros, conforme Tasumi (2003).

Os principais produtos gerados a partir do SEBAL são, o albedo de superfície, balanço de onda curta, balanço de onda longa, índices de vegetação como o NDVI, SAVI e IAF, emissividade de superfície, temperatura de superfície, saldo de radiação, fluxo de calor sensível, calor latente e a evapotranspiração pixel a pixel.

\section{MAPEAMENTO DO SALDO DE RADIAÇÃO DIÁRIO À SUPERFÍCIE}

No tocante ao mapeamento do saldo de radiação à superfície perante o algoritmo SEBAL, o processamento referente à imagem do satélite Landsat-8 (OLI/TIRS), seguiuse os procedimentos que estão explicitados no trabalho de Machado (2016) que analisou as áreas de arenização e areais no Sudoeste de Goiás, via sensoriamento remoto buscando identifica-las e mapeá-las. Neste trabalho supracitado ainda podem ser observados os parâmetros referentes às imagens OLI/TIRS.

Para o mapeamento do Saldo de Radiação diário com as imagens do satélite Landsat-5 foi necessário montar uma tabela (tabela 2) com os valores constantes como requisito de transformações dos níveis digitais das imagens em radiância e reflectância, tais dados foram fornecidos pelo serviço geológico dos E.U.A.

Tabela 02- Mapeador Temático TM Landsat 5: descrição, intervalo de comprimentos de onda e coeficientes de calibração, radiâncias espectrais mínima (a) e máxima (b) e irradiância espectral no topo da atmosfera para imagens até 04/05/2003.

\begin{tabular}{|c|c|c|c|c|}
\hline \multirow[t]{2}{*}{ Descrição dos canais } & \multirow[t]{2}{*}{$\begin{array}{l}\text { Comprimento de } \\
\text { onda }(\mu \mathrm{m})\end{array}$} & \multicolumn{2}{|c|}{$\begin{array}{l}\text { Coeficiente de calibração } \\
\left(\mathrm{Wm}^{-2} \mathrm{sr}^{-1} \mu \mathrm{m}^{-1}\right)\end{array}$} & \multirow[t]{2}{*}{$\begin{array}{l}\text { Constante Solar } \\
\left.\mathrm{m}^{-2} \boldsymbol{\mu m}^{-1}\right)\end{array}$} \\
\hline & & $\mathbf{a}$ & b & \\
\hline Banda 1 (azul) & $0,45-0,52$ & $-1,52$ & 152,0 & 1958,00 \\
\hline Banda 2 (verde) & $0,53-0,61$ & $-2,84$ & 296,81 & 1828,00 \\
\hline Banda 3 (vermelho) & $0,62-0,69$ & $-1,17$ & 204,3 & 1559,00 \\
\hline Banda 4 (infravermelho próximo) & $0,78-0,90$ & $-1,51$ & 206,2 & 1045,00 \\
\hline Banda 5 (infravermelho médio) & $1,57-1,78$ & $-0,37$ & 27,19 & 219,00 \\
\hline Banda 6 (infravermelho termal) & $10,4-12,5$ & 1,2378 & 15,303 & - \\
\hline Banda 7 (infravermelho médio) & $2,10-2,35$ & $-0,15$ & 14,38 & 75,00 \\
\hline
\end{tabular}


As etapas dos cálculos foram realizadas no Erdas IMAGINE 2014, como demonstrado a seguir:

\section{Etapa 1: Radiância}

Esta etapa consiste na conversão dos números digitais (ND) em radiância espectral monocromática que representa a radiação solar refletida e a radiação emitida pela Terra, para as bandas 1,2,3,4,5,6 e 7. Utilizou a equação 01 proposta por Markham e Barker (1986):

$$
\mathrm{L}_{\wedge \mathrm{i}}=a_{i}+\frac{b_{i}-a_{i}}{255} \times N D
$$

Onde a e b correspondem às radiâncias espectrais máximas e mínimas (Wm-2 $\mathrm{sr}^{-}$ $\left.{ }^{1} \mu \mathrm{m}^{-1}\right)$ ND são os níveis digitais de cada pixel da imagem, que variam de 0 a 255 , í são as bandas (1,2,3,4,5,6 e 7) do satélite TM Landsat-5.

\section{Etapa 2: Reflectância}

A reflectância é a razão entre o fluxo de radiação solar refletido pela superfície e o fluxo de radiação global incidente, para tal, utilizou-se a equação 02 proposta por Allen et. al. (2002):

$$
\rho_{\lambda i}=\frac{\pi \cdot L_{\lambda i}}{k_{\lambda i} \cdot \cos Z \cdot d_{r}}
$$

L $\lambda \mathrm{i}$ é a radiância monocromática de cada banda do TM Landsat-5, $\mathrm{K} \lambda \mathrm{i}$ é a irradiância solar no topo da atmosfera de cada banda. Z é o ângulo zenital.

Dr é o inverso do quadrado da distância relativa Terra-Sol de acordo com o dia ao longo do ano. Pode ser encontrada com a equação 03 proposta por Duffie e Beckman (1980):

$\mathrm{dr}=1+0,033 \cos (2 \pi \mathrm{DDA} / 365)$

Sendo DDA o dia sequencial do ano, começando de 1 de janeiro e considerando fevereiro com 28 dias.

\section{Etapa 3: Albedo planetário}

O albedo planetário corresponde ao poder de reflexão da superfície mais a atmosfera e seus componentes para os comprimentos de onda curta $(0,3-3,0 \mu \mathrm{m})$. Sua obtenção se dá através do ajuste linear das reflectâncias espectrais $\rho \lambda$ com pesos $\omega \lambda$ através da equação 04 (GOMES, 2009).

$$
\varpi_{\lambda, b}=\frac{E S U N_{\lambda, b}}{\sum E S U N_{\lambda, b}}
$$

\section{Etapa 4: Albedo corrigido}

O poder refletor da superfície ou albedo de superfície pode ser entendido como o coeficiente de reflexão da superfície para a radiação de onda curta, corrigidos os efeitos atmosféricos. Trata-se de uma medida adimensional que pode ser avaliada pela razão 
entre a radiação direta e a difusa em função do ângulo zenital solar. A obtenção do albedo de superfície se deu por meio da equação 05 recomendada por Allen et. al. (2002).

$$
\alpha=\frac{\alpha_{\text {toa }}-\alpha_{p}}{\tau_{s w}{ }^{2}}
$$

Sendo que, atoa é o albedo planetário e $\alpha$ p é a radiação solar refletida pela atmosfera variando de 0,025 a 0,04 . E $\tau$ sw é a transmissividade da atmosfera que nas condições de transparência calcula-se utilizando a equação 06 de acordo com Allen et. al. (2002).

$$
\tau_{s w}=0,75+2 \times 10^{-5} z
$$

Em que z é a altitude em metros de cada pixel da imagem.

\section{Etapa 5: Saldo de radiação diário}

O saldo de radiação diário segundo De Bruin (1987) pode ser calculado através da equação 07:

$R_{n 24 h}=(1-\propto) R_{s} \downarrow 24 h-\propto \tau_{s w 24 h}$

Em que: $\alpha=$ albedo; Rs $\downarrow 24 \mathrm{~h}=$ radiação solar incidente média diária $\left(\mathrm{W} \mathrm{m}^{-2}\right) ; \alpha=$ coeficiente de regressão entre o saldo de radiação de onda longa diário e a transmissividade atmosférica diária.

\section{RESULTADOS E DISCUSSÃO}

Para compreender as variações do saldo de radiação diário, faz-se necessário analisar a distribuição espacial dos diferentes usos da Terra na bacia. De acordo com a figura 3, os usos da Terra possuem uma grande variabilidade no que tange a espacialização do território na bacia do Rio São Lamberto no período analisado em 1985. Observa-se que, há predominância da vegetação nativa de Cerrado e Mata Seca na extensão territorial da área de estudo, conforme a figura 4:

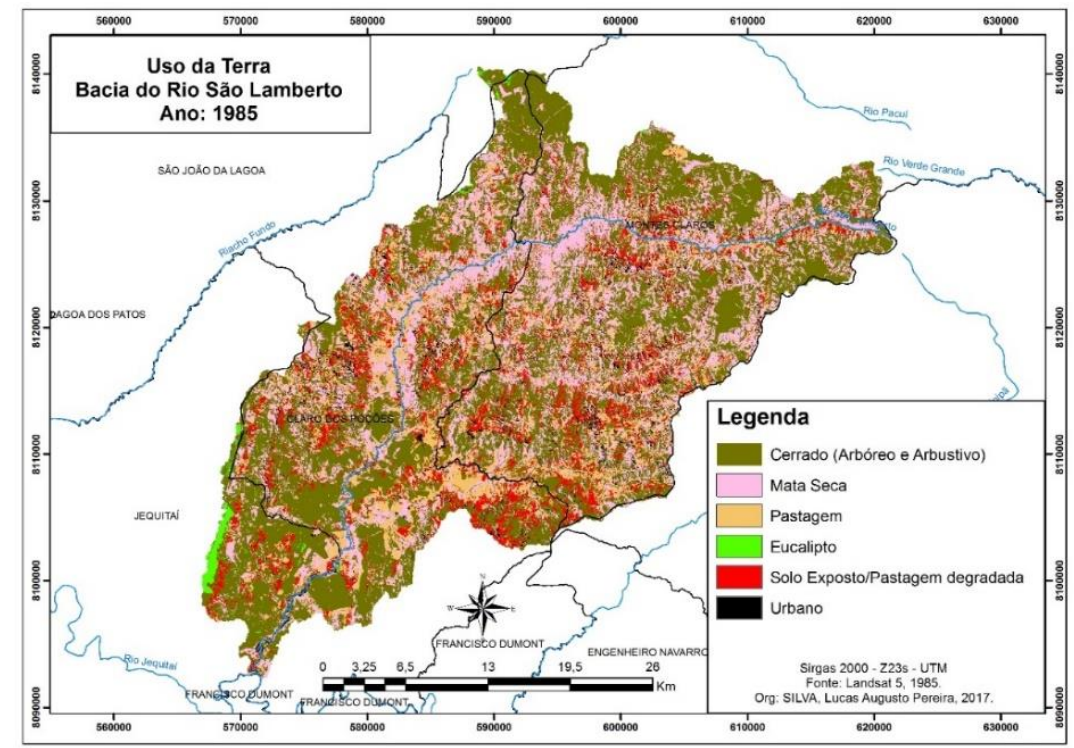

Figura 4- Mapa de uso da Terra da Bacia do rio São Lamberto (28/08/1985). 
Neste período de análise, como foi mencionado, há predominância de vegetação de Cerrado e Mata Seca, estas classes representam cerca de 72,42\% da bacia do rio São Lamberto. Nas áreas destinadas ao Cerrado, pôde-se notar através de foto-leitura que, possuíam no período analisado em 1985 vegetação arbustiva e arbórea.

As áreas com vegetação arbustiva, estão inseridas em grande maioria ao Sul e Sudeste da bacia. As áreas de Cerrado arbóreo estão distribuídas aos topos das serras e/ou áreas com altimetria mais elevada da Bacia, a exemplo ao Norte, Nordeste e Noroeste, isso podendo estar associado às dificuldades encontradas difícil para obter o acesso de áreas com topografia elevada, desta maneira são poucas as atividades a serem desenvolvidas nestas áreas, podendo reforçar esta argumentação acerca da discussão alavancada por Leite e Brito (2010), ao mencionar que, as formas de relevo na superfície influenciam nas atividades humanas.

Tangente ao mapeamento das áreas de pastagens, compreenderam a 14,44\% da distribuição territorial da bacia neste período de análise, obtendo maior atenuação ao Sudeste da bacia, onde estão situadas as áreas mais planas. É notório um avanço significativo dessas áreas de sistemas de pastagens, pois ao observar a figura 3, nota-se a distribuição espacial das áreas de pasto, com intensidade, sendo possível analisar às margens do rio São Lamberto já entradas dessa classe de uso da Terra.

Fato semelhante às áreas de solo exposto/pastagens degradadas, que neste período analisado em 1985, ocupavam cerca de 9,6\% do território. Já é notório a distribuição destas áreas perante o território da bacia, fato este que conduzirá substituição e significante aumento dessa classe e de pastagem (melhorada) dentro de um intervalo de tempo de 31 anos, como será abordado na argumentação do mapeamento do uso da Terra em 2016.

Neste período de análise, a classe compreendida como Eucalipto, ocupava 0,75\% do território da bacia, com maior concentração ao sudoeste da área de estudo, porém, já é possível notar acentuações desta classe ao Noroeste da Bacia, conforme a figura 3.

As áreas mapeadas como Urbano, configuram as áreas de edificações, pavimentações, áreas centrais de cidades e periféricas, neste período analisado, essa classe compreendeu a 2,79\% do território.

Esta classe discutida, no ano de 2016, representou 4,18\% do território da bacia, sofrendo acréscimo de 1,39\% se comparar com o período analisado em 1985, observando diante disto, o crescimento territorial das áreas mapeadas como Urbano, como é observado na figura 5 :

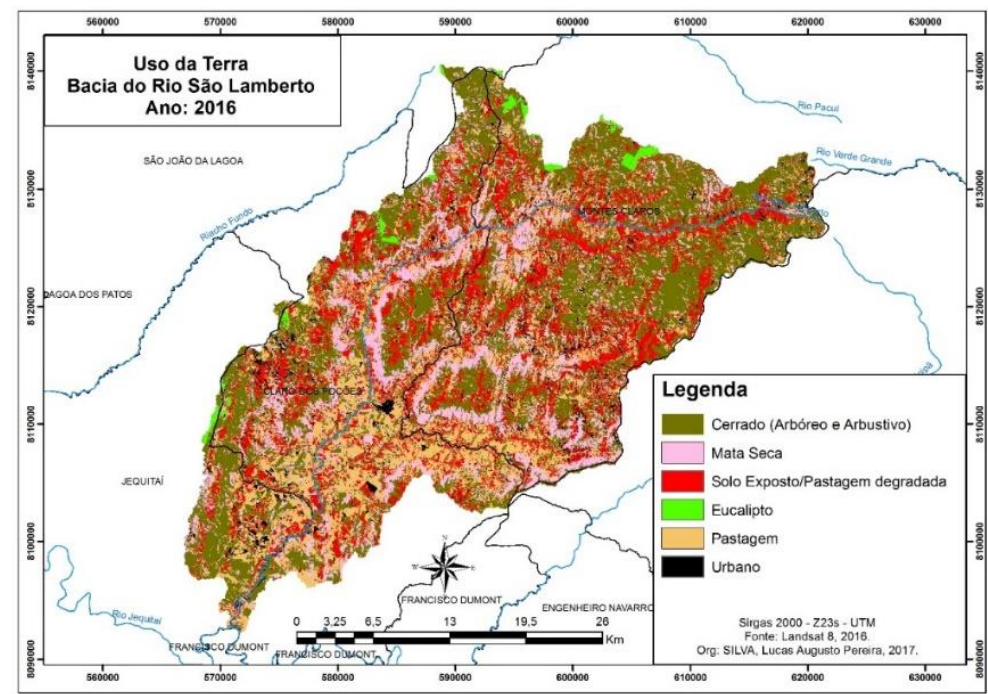

Figura 5- Mapa de uso da Terra da Bacia do rio São Lamberto (16/07/2016). 
Para melhor demonstrar a variação dos usos da Terra fez-se necessário montar um gráfico explicativo (gráfico 1):

\section{Distribuição dos Usos da Terra (\%)}

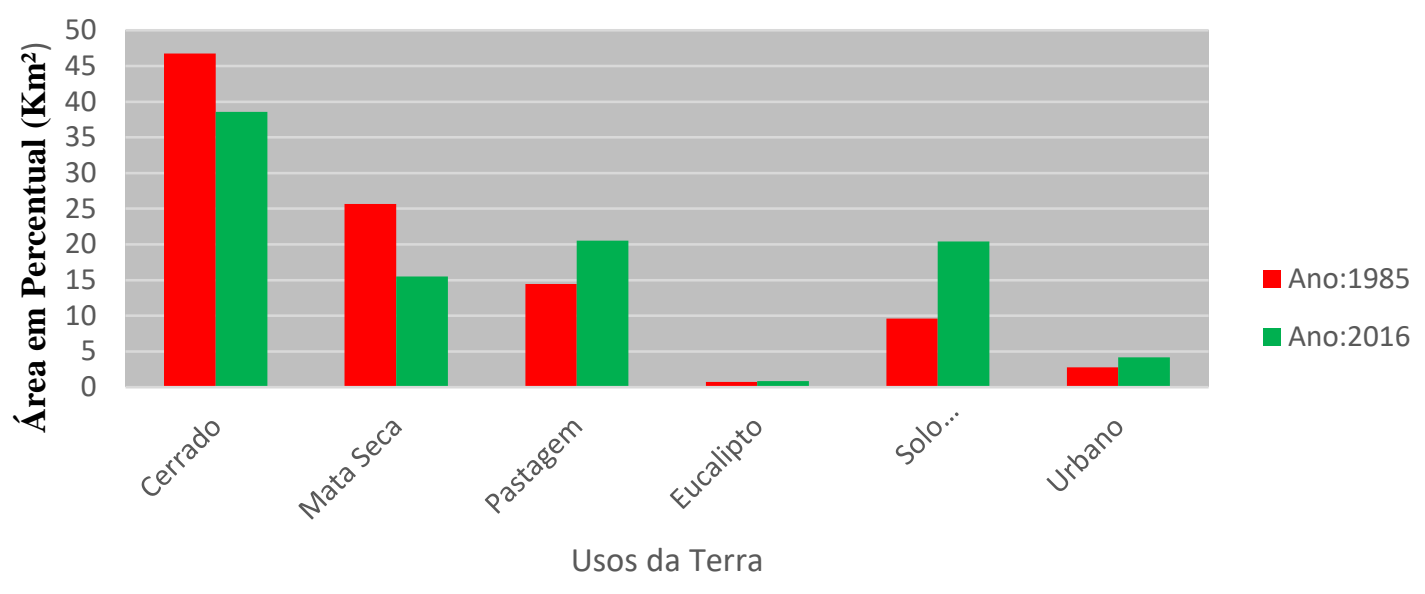

Gráfico 1 - Distribuição dos usos da Terra

As áreas mapeadas como solo exposto, detém um aumento significativo da distribuição do território da bacia, como mencionado em trecho do texto, obtendo aumento de 10,79\% da área estudo, ao comparar os resultados de 1985 e 2016, sendo que, em 2016 esta classe representou 20,39\% do território. Vale ressaltar que, devido a confusão espectral da cena, pôde ter havido mapeamento de áreas de afloramento rochoso dentro desta classe denominada de solo exposto/pastagens degradadas, neste período de análise.

No tocante as áreas de Eucalipto mapeadas no período de 2016, compreenderam a $0,83 \%$ do território, observando assim crescimento desta classe ao comparar com 1985 , este crescimento sendo observado ao Norte e Noroeste da Bacia.

No que tange as classes mapeadas como Pastagem, é notório o crescimento e avanços significativos dentro do intervalo de 31 anos, aumento este que representou 6,12 $\%$ de acréscimo ao comparar de 1985 a 2016, ou seja, representando 20,56\% do território em 2016. Observa-se que as regiões Sul e Sudeste, além das margens do rio São Lamberto, sofreram perturbações significativas no que tange a conversão de mata nativa à pastagem.

Perturbações estas que significaram supressão da extensão de mata nativa em $18,38 \%$, analisando as duas classes nativas (Cerrado e Mata Seca). Sendo que, neste período de análise, a classe mapeada como Cerrado compreendeu 38,55\% do território mapeado, tendo assim decréscimo de 8,19\%, ao comparar com 1985. Já as áreas mapeadas como Mata Seca, sofreram decréscimo de 10,19\%, ao comparar com o período analisado 1985.

Diante do ponto de vista da perda da mata nativa, por intervenções antropogênicas como o desmatamento para plantio agropastoril, tem reflexos significantes na fragmentação dos habitats, influencia diretamente na redução da biodiversidade e o aumento do efeito de borda nos fragmentos das vegetações naturais (CLEMENTE et., al 2017).

A perda extensiva das matas nativas tende a afetar diversas escalas, desde a micro a macro escala, este fato pode conduzir a danos severos nas propriedades do solo, tanto químicas, quanto físicas, através de movimentos de massa. Esta perda, vêm a conduzir variações climáticas à superfície terrestre, pois a vegetação nativa de torna um regulador 
térmico e consequentemente um regulador das variações climáticas em dado ambiente, devido à sua arquitetura e suas demais características, assim, nas figuras 5 e 6, estão demonstrados os mapas do saldo de radiação diário, que é um fator determinante para as variáveis climáticas. Como mencionado, nas figuras 6 e 7 estão os mapas de saldo de radiação diário na bacia, para os anos 1985 e 2016, respectivamente:

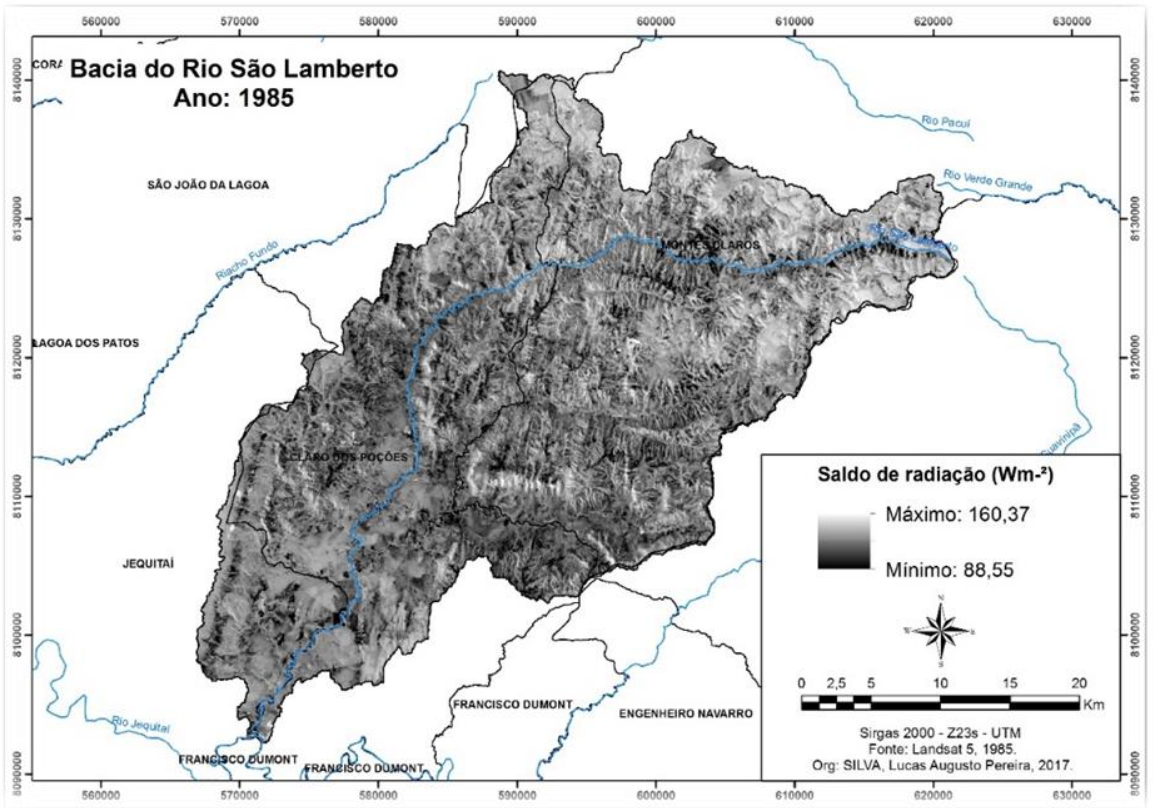

Figura 6- Mapa do saldo de radiação diário da bacia (28/08/1985)

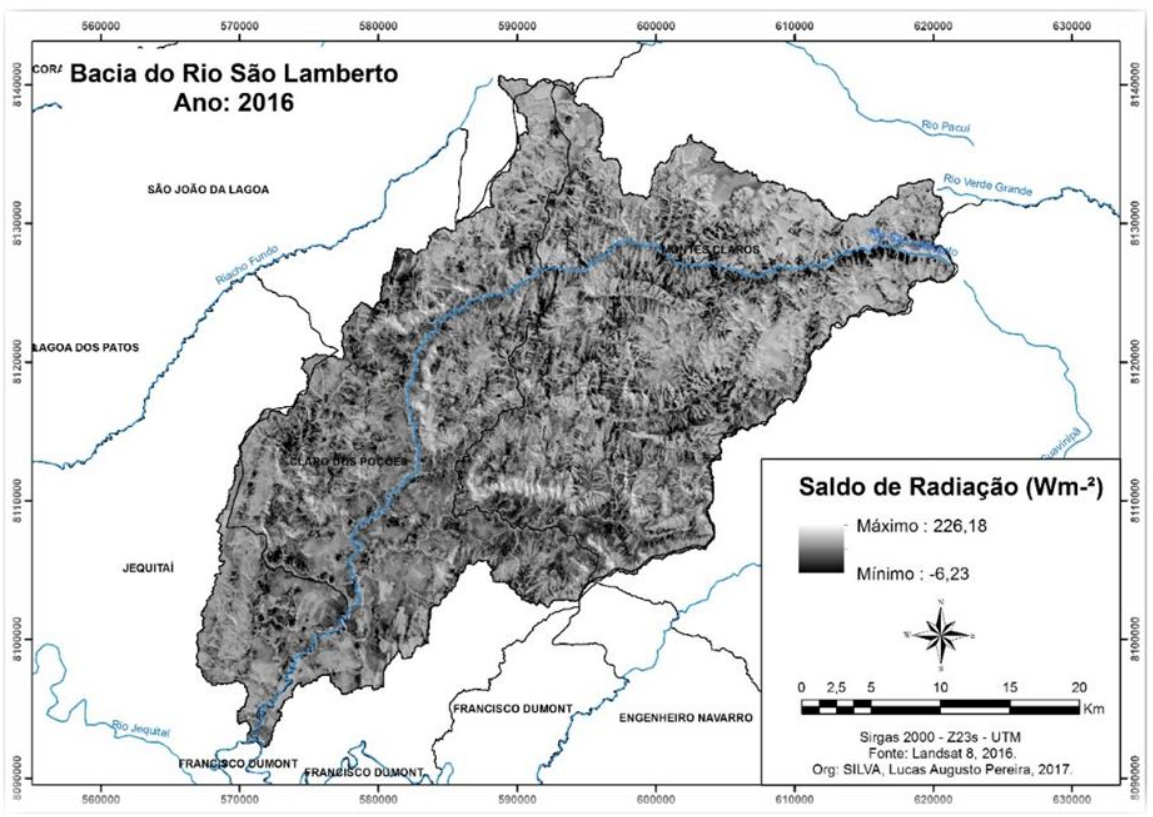

Figura 7- Mapa do saldo de radiação diário da bacia (16/07/2016)

No tocante ao mapeamento do saldo de radiação para os períodos de 1985 e 2016, observa-se as variações existentes em ambos períodos, onde o $\mathrm{Rn} 24 \mathrm{~h}$ varia de 88,55 a $160,37 \mathrm{Wm}^{2}$ para o ano de 1985 e $-6,23$ a $226,18 \mathrm{Wm}^{2}$ para o período analisado em 2016.

Para compreender as variações do saldo de radiação por meio dos diferentes usos da Terra, faz-se necessário analisar a tabela 3 e figura 8 onde tem-se os dados com os valores do saldo de radiação para o ano de 1985: 


\begin{tabular}{lc}
\hline Usos da Terra & Saldo de radiação $\left(\mathbf{W m} \mathbf{-}^{2}\right)$ \\
\hline Mata Seca & 149,94 \\
Cerrado & 150,17 \\
Pastagem & 139,34 \\
Eucalipto & 147,7 \\
Solo exposto/pastagens degradadas & 133,61 \\
Urbano & 140,52
\end{tabular}

Tabela 3- Saldo de radiação dos usos da Terra em 1985.

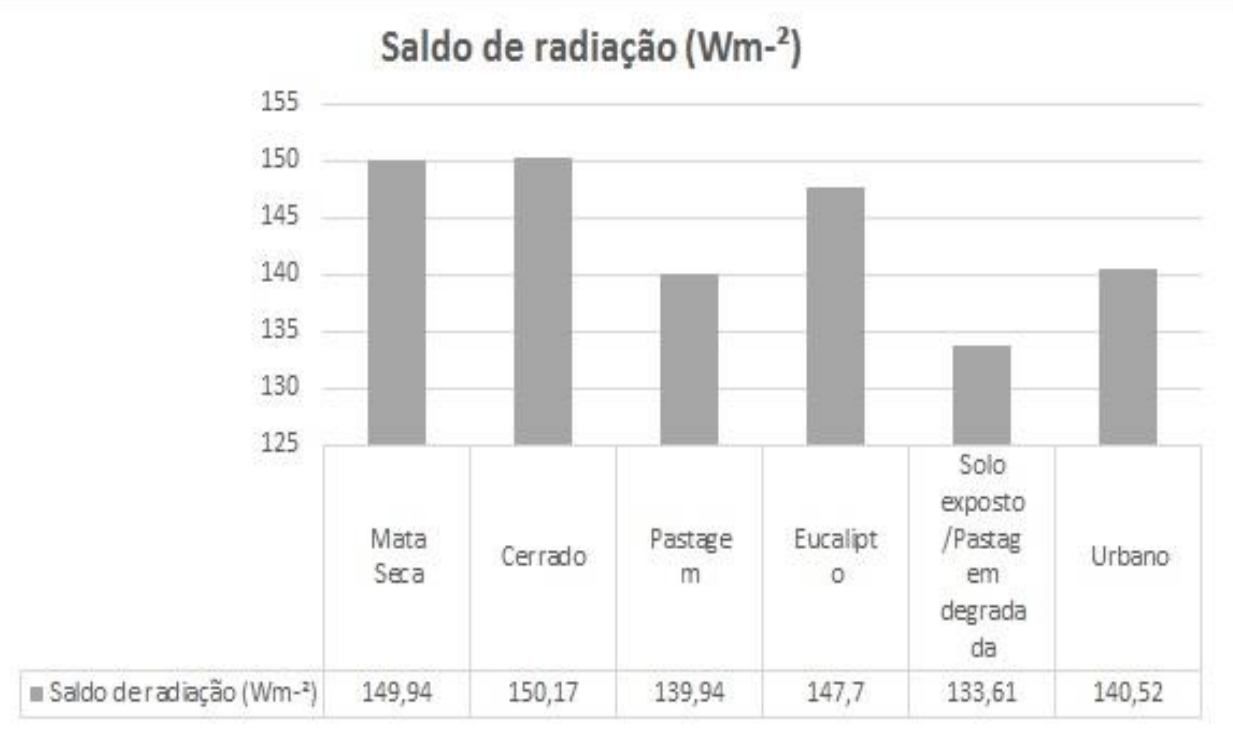

Figura 8- Saldo de radiação em diferentes usos da Terra (1985).

Para a área denominada como mata seca, o saldo de radiação $24 \mathrm{~h}$ médio neste período de análise foi estimado em 149,94 Wm-2 , obtendo valores máximos de $156 \mathrm{Wm}$ 2 e mínimo de $142 \mathrm{Wm}^{2}$. Para os valores mínimos estimados, associa-se às áreas de mata seca muito rala e rasteira, espaçadas e próximas de áreas de solo em exposição e afloramento rochoso. Os valores máximos estão associados às áreas nas amostras com as matas secas em maior conjunto, especificamente às margens do rio São Lamberto, onde neste período de análise há grandes concentrações de mata seca, conforme observa-se na figura 3.

No tocante às áreas de Cerrado, a média do saldo de radiação, estimou-se em 150,17 Wm-2 ${ }^{2}$, aproximando a média obtida na área de mata seca. Neste uso, os valores máximo e mínimo foram de $153 \mathrm{Wm}^{2}$ e $145 \mathrm{Wm}^{2}$ respectivamente, tais valores são muito semelhantes aos valores da mata seca, isto sendo associado às características semelhantes destas formações.

Para os valores máximos de saldo $24 \mathrm{~h}$ de Cerrado, associa-se às áreas de Cerrado Arbóreo, por sua vez, os menores valores estão associados às formações arbustivas. Ao Norte da bacia, coletou-se amostras de Cerrado Arbóreo e ao Sul e Sudoeste áreas de formações arbustivas, justificando desta maneira esta argumentação anterior, pois, a energia utilizada nas áreas com vegetação arbórea tende a ser divergente a utilização pelas formações arbustivas, não divergente no tocante a 'função' da planta propriamente dita, mas sim, no que tange à absorção de energia, onde áreas com a vegetação arbórea tenderá a consumir mais energia, fato contrário das formações arbustivas.

Como de esperado, as áreas de solo exposto/pastagens degradadas apresentaram os menores valores de saldo de radiação, com média de 133,61 Wm-2 ${ }^{2}$ máximo de 139 $\mathrm{Wm}^{2}{ }^{2}$ e mínimo de $127 \mathrm{Wm}^{-2}$. Este fato pode estar associado à falta de vegetação e/ou 
cobertura do solo eficiente, seja antropogênica ou nativa. Estas condições impostas (falta de cobertura eficiente) levariam este uso da Terra a reflexões constantes de radiação solar, por meio de albedo de superfície, e, havendo este maior escape de energia tenderá a afetar o saldo de radiação neste ambiente.

Neste período de análise, as áreas amostradas como Pastagem, apresentaram maiores instabilidades em seus valores de saldo de radiação, onde seu valor médio foi computado em 139,34 Wm-2 ${ }^{2}$, já os valores máximos e mínimos foram estimados em 142 $\mathrm{Wm}^{-2}$ e $136 \mathrm{Wm}^{-2}$, respectivamente. Esta instabilidade, pode estar associada aos fatores sazonais, ou até mesmo o regime hídrico que estas áreas sofrem (VELOSO et. al., 2017).

No tocante às amostras estabelecidas para a área Urbana, entende-se como comportamento padrão, devido a alta reflexão de energia que estas áreas ocasionam, afetando diretamente o balanço radiativo nestes ambientes. A média estimada foi registrada em 140,52 $\mathrm{Wm}^{2}$, já os valores mínimo e máximo foram respectivamente estimados em $137 \mathrm{Wm}^{2}$ e $144 \mathrm{Wm}^{2}$.

As áreas amostradas como eucalipto, obtiveram valores médios de saldo de radiação de $147,7 \mathrm{Wm}^{2}$, e possuindo valor mínimo de $142 \mathrm{Wm}^{2}$ e máximo aproximado em $152 \mathrm{Wm}^{2}$. Neste período os valores de saldo de radiação do eucalipto assemelhamse com os valores das áreas nativas, principalmente as áreas arbóreas, fato este estando associado à energia utilizada nos processos bioquímicos do eucalipto, processos como a evapotranspiração que requer maior quantidade de energia para seu seguimento.

Para o período analisado em 2016, esta classe detém comportamento semelhante às amostradas do período analisado em 1985, obtendo assim, valor médio de saldo de radiação de 187,8 $\mathrm{Wm}^{2}$. Os valores mínimo e máximo, foram estimados em $179 \mathrm{Wm}^{2} \mathrm{e}$ 196 Wm- $^{2}$, mais uma vez mostrando comportamento de tendência a obter maiores quantidades de energia para os seus demais processos. Nestas áreas, antes da classificação, foram observadas características de coberturas densas, justificando estes valores, conforme a tabela 4 e figura 9 :

\begin{tabular}{|l|c|}
\hline Usos da Terra & Saldo de radiação $\left(\mathbf{W m}^{2}\right)$ \\
\hline Mata Seca & 151 \\
\hline Cerrado & 190 \\
\hline Pastagem & 168,91 \\
\hline Eucalipto & 187,8 \\
\hline Solo exposto & 140,85 \\
\hline Urbano & 157,8 \\
\hline
\end{tabular}

Tabela 4- Saldo de radiação dos usos da Terra em 2016.

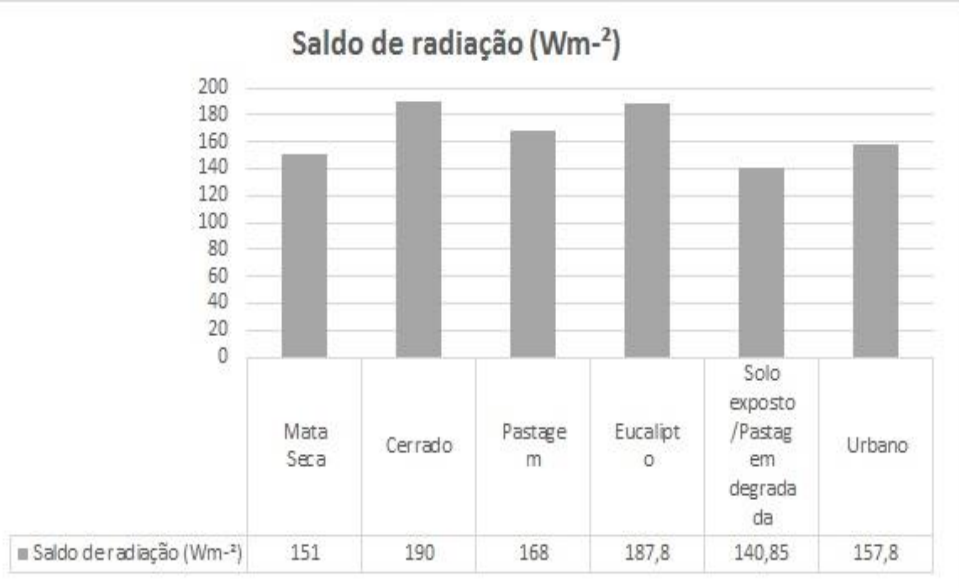

Figura 9- Saldo de radiação em diferentes usos da Terra (2016). 
O comportamento do uso de energia nas áreas de Cerrado, segue a tendência do período analisado em 1985, esta classe em 2016, obteve valores mínimo, médio e máximo estimados em $179 \mathrm{Wm}^{-2}, 187,8 \mathrm{Wm}^{-2}$ e $199 \mathrm{Wm}^{-2}$ respectivamente. Nas áreas amostradas como Cerrado, foram selecionadas áreas de vegetação arbórea, principalmente ao norte da Bacia, uma vez que, é onde se concentram as maiores extensões de Cerrado Arbóreo, mais especificamente em áreas de topografia elevada. Comportamento semelhante às áreas de Cerrado, possuem as áreas de mata seca, com valor médio de saldo de radiação estimado em $151 \mathrm{Wm}^{-2}$ e valores mínimo e máximo de $119 \mathrm{Wm}^{-2} 180 \mathrm{Wm}^{-2}$.

No que tange as áreas de pastagem, no período analisado em 2016, o valor médio estimado para esta classe, foi de $168,91 \mathrm{Wm}^{2}$, acompanhado dos valores mínimo e máximo de $148 \mathrm{Wm}^{2}$ e $187 \mathrm{Wm}^{2}$, respectivamente. Mostrando comportamento semelhante ao período analisado em 1985.

Atenta-se para um dado interessante, que é o fato do valor do saldo de radiação da área urbana ser relativamente elevado, obtendo $157,8 \mathrm{Wm}^{2}$ de valor médio e $151 \mathrm{Wm}^{2}{ }^{2}$ e $162 \mathrm{Wm}^{2}$ de valores mínimo e máximo, este comportamento está explicitado devido às áreas verdes urbanas analisadas na imagem por meio de foto-leitura, isto causando tal instabilidade nos valores de saldo de radiação.

No tocante às áreas amostradas como solo exposto/pastagens degradadas no período analisado do ano de 2016, os valores mínimo, médio e máximo, foram estimados em $96 \mathrm{Wm}^{2}, 140,85 \mathrm{Wm}^{2}$ e $177 \mathrm{Wm}^{-2}$, mostrando desta maneira o comportamento de tendência representado para o período analisado do ano de 1985.

Ao analisar a tendência do saldo de radiação em diferentes usos da Terra, analisouse as médias das duas cenas e, para o período analisado em 1985, a média do saldo de radiação da bacia foi estimada em 143,7 Wm-2 . Este valor médio se aproxima dos valores das áreas de Cerrado e Mata Seca, consequentemente por $72,42 \%$ da extensão da bacia ser composta por estas classes no período analisado. Tangente a média da bacia no período analisado em 2016, obteve valor de $178,5 \mathrm{Wm}^{2}$, mantendo relação intrínseca com as áreas de pastagem e solo exposto e porções de Cerrado arbustivo.

De maneira analítica, ao analisar os comportamentos, máximos, mínimos e médios, montou-se uma tabela com a intenção de demonstrar a tendência do comportamento do saldo de radiação dos diferentes tipos de usos da Terra, tendo como parâmetros os valores estimados. Para os usos com tendência de menores valores de saldo de radiação usou-se a expressão " < " e, para os maiores valores a expressão " > ", como demonstrado na tabela 5:

\begin{tabular}{|l|l|}
\hline Usos da Terra & Tendência do saldo de radiação \\
\hline Mata Seca & $>$ \\
\hline Cerrado & $>$ \\
\hline Pastagem & $<$ \\
\hline Eucalipto & $>$ \\
\hline Solo Exposto/pastagens degradadas & $<$ \\
\hline Urbano & $<$ \\
\hline
\end{tabular}

Tabela 5- Tendência do saldo de radiação nos usos da Terra

Vale ressaltar que, a tendência demonstrada para o saldo de radiação $24 \mathrm{~h}$, foi estabelecida para os resultados inseridos nesta pesquisa, nas condições abióticas e bióticas apresentadas na área de estudo. 


\section{CONSIDERAÇÕES FINAIS}

Neste trabalho foi possível observar a relação intrínseca entre os sistemas de usos da Terra e os fenômenos climatológicos, neste caso específico, o saldo de radiação diário, apresentando linhas de tendência entre os sistemas de usos da Terra, a qual foi demonstrada na tabela 5 .

Outro fato que conduziu a discussão desta pesquisa, foi a grande rotação dos sistemas de usos da Terra na bacia do rio São Lamberto, onde, observou-se os avanços das áreas de solo exposto/pastagens degradadas e de sistemas de pastagens ao longo dos anos mapeados, isto tendo reflexo significante nos valores médios de saldo de radiação diário da bacia, como foi apresentado.

Os produtos orbitais em conjunto ao SEBAL e as técnicas de sensoriamento remoto foram de extrema importância e eficiência, obtendo neste trabalho resultados significativos e satisfatórios.

\section{Referências Bibliográficas}

ALLEN, R. G.; TASUMI, M.; TREZZA, R. SEBAL (Surface Energy Balance Algorithms for Land) Advanced Training and Users Manual - Idaho Implementation, $2002.97 \mathrm{p}$.

BASTIAANSSEN, W.G.M. et al. A remote sensing surface energy balance algorithm for land (SEBAL): 1. Formulation. Journal of Hydrology, v. 212- 213, p. 198-212, dez. 1998a.

Banco de Dados Geomorfométricos do Brasil. Disponível em: http://www.dsr.inpe.br/topodata/. Acesso em Setembro de 2017.

BASTIAANSSEN, W.G.M. et al. A remote sensing surface energy balance algorithm for land (SEBAL): 2. Validation. Journal of Hydrology, v. 212-213, p. 213-229, dez. 1998 b.

BASTIAANSSEN, W.G.M. SEBAL - Based Sensible and Latent Heat Fluxes in the Irrigated Gediz Basin, Turkey. Journal of Hydrology, v. 229, p. 87-100, mar. 2000.

BISHT, G.; BRAS, R. L. Estimation of net radiation from the MODIS data under all sky conditions: Southern Great Plains case study. Remote Sensing of Environment, v. 114, n.7, p. 1522-1534, 2010.

CLEMENTE, M.S.C.; SANTOS, P.S. 2017. Geotecnologias como suporte para análise da vegetação natural na sub-bacia hidrográfica do rio Gavião (1988 A 2015). Revista Cerrados - Montes Claros/MG, v.15, n. 1, p.99-113, jan/jun-2017.

DE BRUIN, H. A. R. From Penman to Makkink. In: HoogharT, J. C. (Ed.), Proceedings and information: TNO Commitee on Hydrological. Gravennhage, The Netherlands, v. 39, p. 5-31, 1987.

DUFfiE, J.A., BECKMAN, W.A., 1980. Solar Engineering of Thermal Process, 1st ed. John Wiley and Sons, NY.

EMPRESA BRASILEIRA DE PESQUISA AGROPECUÁRIA - EMBRAPA. Sistema Brasileiro de Classificação de Solos. 2. ed. Rio de Janeiro: Embrapa, 2006. 306 p.

FERNANDES, M. D. ; OLIVEIRA, G. H. G. ; NOBRE, B. A. . SENSORIAMENTO REMOTO E SIG APLICADO NO USO E OCUPAÇÃO DO SOLO NA BACIA DO RIO SÃO LAMBERTO NO NORTE DE MINAS GERAIS. In: II Colóquio Cidade e Região: Urbanidades e Ruralidades Contemporâneas, 2012, Montes Claros/MG

FOSTER, P. et al. Changes in atmospheric constituents and in radiative forcing, Climate Change: The Physical Science Basis, Cambridge University Press, Cambridge, UK/New York USA, 2007. 
GOMES, H. F. B. Balanços de radiação e energia em áreas de cultivo de cana-de açúcar e cerrado no estado de São Paulo mediante imagens orbitais. 2009. Tese (Doutorado) - Universidade Federal de Campina Grande, Paraíba. 2009

IBGE, Instituto Brasileiro de Geografia e Estatística. Disponível em: 〈http://www.ibge.gov.br〉. Acesso em Setembro de 2017.

LILLESAND, KIEFER E CHIPMAN. Remote Sensing and Image Interpretation. Wiley; 6 edition (November 6, 2007).

LEITE, M.R. 2011. Sensoriamento remoto aplicado à Análise temporal da relação uso da Terra/Temperatura e Albedo de superfície na Bacia hidrográfica do Rio Vieira no Norte Minas Gerais. 2011. Dissertação (Mestrado em Geografia) Universidade federal de Uberlândia, Uberlândia/MG.

LEITE, M. R.; BRITO, J.L.S. Sensoriamento remoto aplicado à Análise temporal da relação uso da Terra/Temperatura e Albedo de superfície na Bacia hidrográfica do Rio Vieira no Norte Minas Gerais. Revista Brasileira de Climatologia v. 10, p. 98, 2012.

Machado, L.M. 2016. Áreas de arenização e areais no Sudoeste de Goiás: O uso do sensoriamento remoto para identificação e mapeamento. Goiás. 2016. Dissertação (Mestrado em Geografia) Universidade Federal de Goiás. 2016.

MARKHAM, B. L.; BARKER, J. L. Landsat MSS and TM post-calibration dynamic ranges, exoatmospheric reflectances and at-satellite temperatures, EOSAT Landsat Technical Notes, v. 1, p. 3-8, 1986.

MENESES, P. R.; SANO, E. E. Classificação Pixel a Pixel de Imagens. In: Introdução ao Processamento de Imagens de Sensoriamento Remoto. Meses, P. R; Almeida, T. de. (Org.). Brasília, 2012.

PEREIRA, C.C. 2014. Temperatura de Superfície na Bacia da Usina Hidrelétrica (UHE) Barra dos Coqueiros, utilizando climatologia e sensoriamento remoto. Goiás.2014. Dissertação (Mestrado em Geografia) - Universidade Federal de Goiás. 2014.

SILVA, B. B.; LOPES, G. M.; AZEVEDO, P. A. determinação do albedo de áreas irrigadas com base em imagens LANDSAT 5-TM. Revista Brasileira de Agrometeorologia, Sete Lagoas - MG, v. 13, n. 2, p. 201-211, 2005.

SILVA, B. B. da.; BRAGA, A. C.; BRAGA, C. C. Balanço de radiação no perímetro irrigado São Gonçalo - PB mediante imagens orbitais. Revista Caatinga, Mossoró - RN, v. 24, p. 145-152, 2011.

SILVA, B.B. et al. Evapotranspiração e estimativa da água consumida em perímetro irrigado do Semiárido brasileiro por sensoriamento remoto. Pesquisa Agropecuária Brasileira, v. 47, n. 9, p. 1218-1226, 2012.

SOUZA, J. D.; SILVA, B. B. da.; CEBALLOS, J. C. Estimativa da radiação solar global à superfície usando um modelo estocástico: caso sem nuvens. Revista Brasileira de Geofísica, Rio de Janeiro - RJ v. 26, p. 31- 44, 2008. 